\title{
AS INFLUÊNCIAS RACIAIS NA CONSTRUÇÃO DO CAMPO ETNOGRÁFICO: UM ESTUDO MULTISSITUADO NO CONTEXTO BRASIL-CANADÁ
}

\author{
Racial influences in the construction of the ethnographic fieldwork: \\ a multi-sited study in the Brazil-Canada context
}

Josiane Silva de Oliveira*

\section{RESUMO}

A predominância do mito do etnógrafo assexuado e não racializado, já debatido na área da Antropologia, fez com que em muitos estudos etnográficos a busca pela neutralidade de desenvolvimento do trabalho de campo silenciasse como questões de gênero e de raça, por exemplo, influenciam o desenvolvimento de pesquisas nas organizações. No intuito de contribuir para sanar essa limitação teórica e empírica dos estudos, o objetivo deste artigo é discutir as influências das relações raciais na construção do campo etnográfico. Para tanto, destacamos o processo de construção de um estudo etnográfico multilocalizado realizado no contexto organizacional do circo contemporâneo. A pesquisa, realizada entre os anos de 2011 e 2013 no Brasil e no Canadá, enfatiza a construção da pesquisadora em termos de raça nos contextos estudados, ressaltando como questões culturais locais dos diferentes países influenciaram a entrada da pesquisadora em campo, o acesso a informações, e, consequentemente, o desenvolvimento da etnografia no campo organizacional estudado. Como contribuição aos estudos organizacionais, debatemos que as pesquisas qualitativas nas organizações não podem ser pensadas com base na neutralidade do/a pesquisador/a no trabalho de campo e que as relações raciais influenciam os modos de condução das etnografias organizacionais, inclusive em contextos transnacionais.

Palavras-chave: Raça. Subjetividade. Etnografia. Organizações. Circo.

\section{ABSTRACT}

The predominance of the myth of the asexual, non-racialized ethnographer, long debated in the scope of Anthropology, has led many ethnographic studies to search for neutrality in the fieldwork, thus silencing how matters of gender and race, for example, influence the development of research in organizations. Aiming to contribute to tackle this theoretical and empirical limitation, the objective of this paper is to discuss the influences of race relations on the ethnographic fieldwork structure. For this purpose, we emphasize the process of building a multi-sited ethnographic study carried out in the organizational context of the contemporary circus. The study was carried out between the years of 2011 and 2013 in Brazil and Canada and emphasizes the development of the researcher in ter$\mathrm{ms}$ of race issues in the contexts studied by stressing how the different countries' local cultural questions influenced her introduction in the field, her access to information and, consequently, the elaboration of the ethnography in the organizational field studied. As a contribution to organization studies, we argue that qualitative surveys carried out in organizations cannot be elaborated based on the supposed neutrality of the researcher in the fieldwork, and that race relations influence how organizational ethnographies are conducted, which includes transnational contexts.

Keywords: Race. Subjectivity. Ethnography. Organizations. Circus.

\footnotetext{
* Professora Adjunta do Programa de Pós-graduação em Administração da Universidade Estadual de Maringá e do Programa de Pós-graduação em Administração da Universidade Federal de Goiás. Doutora em Administração pela Universidade Federal do Rio Grande do Sul. E-mail para contato: oliveira.josianesilva@gmail.com.
} 


\section{INTRODUÇÃO}

É

concreto que a etnografia esteja se estabelecendo como um importante método de pesquisa nos estudos organizacionais (ALCADIPANI; WESTWOOD; ROSA, 2015; FANTINEL; CAVEDON; FISCHER, 2014; GHERARDI, 2012; CARRIERI; SARAIVA, 2007) e diferentes prismas analíticos estejam se estabelecendo para compreender distintas formas de incorporação da etnografia para a compreensão dos processos organizativos (OLIVEIRA; CAVEDON, 2015; FIGUEIREDO, 2015; 2013; FLORES-PEREIRA; DAVEL; CAVEDON, 2008). Contudo, esse tipo de estudo ainda apresenta uma lacuna teórica e empírica de entendimento sobre como desconstruir o mito da neutralidade do pesquisador no desenvolvimento da etnografia, apresentando em relatos etnográficos como questões raciais influenciam o trabalho de campo (DEWALT; DEWALT, 2011; PINHO, 2008; GROSSI, 1992).

Se raça ainda é um conceito negado do ponto de vista teórico nos Estudos Organizacionais, conforme destacam Conceição (2009) e Rosa (2014), em termos de método de pesquisa, representa um debate silenciado e ainda carente de abordagem no campo de pesquisas em Administração no Brasil. A relevância de se discutir raça na prática de pesquisa ocorre por esta ser uma das categorias sociais estruturantes da sociedade brasileira, portanto não há como separar a prática da pesquisa das práticas cotidianas da sociedade brasileira, bem como do campo científico como um todo (NOGUEIRA, 2007; GONZALES; HASENBALG, 1982).

O silenciamento das discussões sobre raça na prática de pesquisa, conforme aponta Pinho (2008), está relacionado à construção dos negros como "problema de pesquisa" e não como pesquisadores. Desse modo, o silenciamento dessas discussões também afeta a persistência da desigualdade racial característica da sociedade brasileira, cujo um dos efeitos é a produção do "lugar" dos negros nos estratos socioeconômicos mais baixos do país, assim como "fora" da universidade, sendo circunscritos a "problemas de pesquisa" (PINHO, 2008).

No intuito de contribuir para sanar essas lacunas teóricas e empíricas em pesquisas, o objetivo deste estudo é compreender as influências das relações raciais na construção do campo etnográfico. Para tanto, realizamos uma construção teórica de debates sobre relações raciais nos Estudos Organizacionais e a subjetividade na construção do trabalho de campo etnográfico. É preciso destacar que a incorporação do tema "raça" não ocorre no sentido de colocar em discussão o tema da diversidade, mas sim de destacar como questões raciais podem ser incorporadas a pesquisas nos Estudos Organizacionais não somente em termos teóricos, mas também na condução do trabalho de campo. Por essa razão consideramos raça a partir de uma abordagem de construção da subjetividade dos pesquisadores no trabalho de campo.

Assim como Hall (1999), consideramos raça como uma categoria discursiva e não biológica funcionando como marcas simbólicas que diferenciam socialmente um grupo de outro. Desse modo, conforme debate Sansone (2004), o problema fundamental quando se discute raça não está em seu conteúdo semântico com determinação biológicas, rejeitado pelos cientistas, mas nas práticas racistas que hierarquizam, desumanizam e justificam a discriminação racial. Ainda para o referido autor, as propostas de combate ao racismo não 
estão no abandono do conceito de raça, visto que o racismo é uma ideologia que pode parasitar tantos outros conceitos, a exemplo de gênero, mas na compreensão social e política da produção e dos efeitos desse fenômeno na sociedade (SANSONE, 2004). Nos Estudos Organizacionais isso se torna relevante na medida em que raça se constitui como prática material e simbólica de composição das relações sociais no cotidiano nas organizações. Ou seja, quando discutimos organizações também estamos nos atentando para como essas produções simbólicas e materiais, a exemplo da raça, têm efeitos políticos no cotidiano de trabalho, inclusive de pesquisa.

Para o desenvolvimento desta proposta de debate, utilizamos a etnografia multissituada (MARCUS, 1999) realizada com um circo contemporâneo (PARKER, 2011) na cidade de Pelotas, Brasil, durante o ano de 2011, e com outro circo na cidade de Montréal, Canadá, ao longo de 2013, destacando como questões raciais influenciaram a condução do estudo etnográfico, evidenciando os jogos políticos entre a pesquisadora e pesquisados que delimitaram a pesquisa de campo.

Os principais resultados da pesquisa destacam como as relações raciais são marcadores de posicionamentos sociais na produção científica do trabalho de campo, especialmente no desenvolvimento de estudos qualitativos etnográficos. Também destacamos que as relações raciais não podem ser pensadas isoladamente de outras categorias sociais, sendo, neste estudo, perpassadas transversalmente por questões de gênero e de nacionalidade.

Conforme discutem DeWalt e DeWalt (2011), é importante se debater questões de gênero, raça e de sexualidade, por exemplo, nos estudos etnográficos, pois são categorias sociais que posicionam os pesquisadores e os sujeitos em campo. Entretanto, ainda para os referidos autores, esses temas são silenciados nas pesquisas devido à necessidade de "neutralidade" científica em relação ao desenvolvimento metodológico das pesquisas, ainda que em termos teóricos esta tenha sido desconstruída nos Estudos Organizacionais.

Concordamos com Pinho (2008) quando o referido autor destaca que a objetividade buscada pela produção de rigor científico nos métodos de pesquisas não pode resultar na alienação dos debates das condições sociais nas quais o texto etnográfico se constitui. Sendo assim, como contribuição às discussões da área de Estudos Organizacionais apresentamos como "raça" atua como uma "permissão simbólica" no acesso e construção do campo de pesquisa, especialmente etnográfico; debatemos a etnografia multissitada como estratégia etnográfica para o estudo de processos organizativos multilocalizados, bem como esperamos produzir espaços de debates sobre como as relações raciais influenciam o trabalho de campo dos pesquisadores nas organizações.

Para o desenvolvimento de tais debates, o artigo está estruturado em seis seções, além desta introdução. Primeiramente, discutimos como as questões raciais têm sido incorporadas aos Estudos Organizacionais no Brasil, seguido dos debates sobre subjetividade na prática etnográfica. A seguir, apresentamos os procedimentos metodológicos utilizados no trabalho de campo, destacando no que consiste a etnografia multissituada. Os resultados da pesquisa etnográfica são apresentados em duas seções: uma sobre o Brasil e outra sobre o Canadá. Ao final, apresentamos as considerações finais do artigo, enfatizando as influências das relações raciais nas etnografias organizacionais. 


\section{RELAÇÕES RACIAIS COMO TEMA DE PESQUISA NOS ESTUDOS ORGANIZACIONAIS}

Apesar da efetiva produção acadêmica sobre a temática "raça" nas Ciências Sociais, na área de Administração pouco se tem debatido sobre o tema (NASCIMENTO et al., 2013; ROSA, 2012; CONCEIÇÃO, 2009). Ainda que raça tenha sido desconstruído enquanto categoria de segregação biológica, em termos sociais e políticos é inegável que esse conceito de análise ainda esteja vigente, visto que nas relações sociais a raça é um fenômeno social arbitrário de estruturação histórica da sociedade brasileira. Nesse sentido, retomamos as discussões de Hall (1999, p. 62), que o considera raça como sendo:

[...] categoria discursiva e não uma categoria biológica. Isto é, ela é uma categoria organizadora daquelas formas de falar, daqueles sistemas de representação e práticas sociais que utilizam um conjunto frouxo, frequentemente pouco específico, de diferenças em termos de características físicas e corporais - cor da pele, textura do cabelo, características físicas e corporais, etc. - como marcas simbólicas, a fim de diferenciar socialmente um grupo do outro.

Assumir o conceito de raça para as análises sociais, conforme apresenta Hall (1999), se refere ao processo de compreensão de como a sociedade se organiza em torno de suas diferenças sociais. No caso brasileiro, debater raça é colocar em pauta, por exemplo, como tais diferenças se tornaram base de uma estrutura de organização social que historicamente tem marginalizado a população negra da dimensão socioeconômica no país, em termos de ocupação de postos de trabalho, por exemplo, até nos processos de ocupação de espaços sociais. Processo este que pode ser observado nos debates sobre as políticas de ações afirmativa, e até mesmo em termos afetivos, conforme discutem Pacheco (2013) e Alves (2010).

Seja em termos subjetivos ou materiais, raça é um fator importante para a dinâmica das relações sociais no Brasil. Comecemos os debates em torno dos dados estatísticos. De acordo com dados do Instituto Brasileiro de Geografia e Estatística (IBGE), a partir de dados do censo demográfico brasileiro do ano de 2010 (IBGE, 2015), a população brasileira é composta por $50,94 \%$ de pessoas que se autodeclaram como pretas ou pardas, $47,51 \%$ como brancas, $1,1 \%$ amarela, $0,43 \%$ como indígena e $0,02 \%$ sem declaração. A renda mensal média dos brasileiros é de $R \$ 1.222,90$ (IBGE, 2015). Caso o indivíduo seja branco, esse valor aumenta para $\mathrm{R} \$ 1.607,76$ e retrai para $\mathrm{R} \$ 921,18$ se for negro (IBGE, 2015).

Cercchetto e Monteiro (2006) afirmam que as pesquisas sobre questões raciais no país têm revelado uma dissonância entre o que os indivíduos pensam em relação à raça no Brasil, normalmente assumindo a existência do racismo, e a autopercepção do racismo, na qual as pessoas afirmam não terem atitudes racistas. Tendo por base, por exemplo, esses dados do IBGE (2015), reconhece-se a existência de diferenças sociais entre negros e brancos no país, porém, a adoção de práticas antirracistas que visam cessar esse processo ainda é vista como um teor conservador no Brasil e acaba-se por reproduzir o racismo na vida cotidiana das pessoas. Racismo se refere ao ato de discriminar um indivíduo ou grupo social em termos raciais. A diferença em relação aos atos preconceituosos ocorre porque no 
segundo caso há uma disposição desfavorável em relação aos membros de uma população, o que pode ser denominado de preconceito (NOGUEIRA, 2007). Quando essa disposição desfavorável limita o acesso dos indivíduos aos bens simbólicos e materiais produzidos pela sociedade, resultando na criação de condições de confirmação dos estigmas que sustentam o preconceito em termos de raça, configuram-se as práticas racistas (NOGUEIRA, 2007). A reprodução desses estigmas ocorre, inclusive, nos espaços acadêmicos, a exemplo do movimento eugênico do racismo científico que utilizava elementos científicos para justificar a discriminação racial e a superioridade da população branca em detrimento dos negros (MUNANGA, 2006).

Essa atitude racista não ocorre somente em termos econômicos, mas constitui a vida subjetiva da sociedade. Sansone (2004), em um estudo etnográfico no qual discutiu a construção da etnicidade na Bahia contemporânea, destaca que os sujeitos pesquisados não dividiam simplesmente sua vida cotidiana entre brancos e negros, mas a classificavam num continuum com base na ideia de "quase todos brancos" e no outro a de "quase todos pretos". Quanto mais um espaço social se aproxima da ideia de "mais branco", mais difícil de ser acessado pelos negros ele se torna, portanto, raça se constituía como importante fator de orientação das relações sociais e de poder (SANSONE, 2004).

Com base nessas considerações sobre as relações raciais, Sansone (2004) debate a produção de três tipos de espaços sociais no contexto estudado, sendo estes os "leves", os "pesados" e os "espaços negros". Os "espaços negros" se caracterizam por serem abertos às discussões sobre negritude, pois os negros "estão no poder" e ser negro é um fator de integração e não de segregação, a exemplo dos terreiros de candomblé ou da capoeira (SANSONE, 2004). Os "espaços leves" são aqueles nos quais as distinções sociais eram vistas como ligadas à classe, à idade, à vizinhança e ao sexo, portanto, em termos raciais são "leves", mas podendo ser "pesados" para outras categorias sociais.

Já as áreas "pesadas" são os espaços nos quais as relações raciais demarcam e hierarquizam a constituição social (SANSONE, 2004). São estes o trabalho, em especial no que concerne a busca por emprego, o namoro e o casamento, e as interações com a polícia (SANSONE, 2004). O local de trabalho foi descrito por quase $70 \%$ dos sujeitos pesquisados por Sansone (2004) como local de manifestação extrema do racismo. 0 espaço afetivo, do casamento e dos encontros amorosos também foram descritos como pautados com fortes manifestações de racismo no país (SANSONE, 2004).

Alves (2011), por exemplo, retoma os debates de que o início da "mestiçagem brasileira" ocorreu, em grande medida, pela violência sexual dos senhores contra suas escravas. Por outro lado, ainda de acordo com Alves (2011), na sociedade contemporânea existe a construção simbólica de "branca para casar, negra para trabalhar e a mulata para as relações sexuais", por isso o índice de mulheres negras com relações afetivas estáveis no Brasil é significativamente menor se comparado às mulheres brancas, o que também é corroborado nos debates propostos por Pacheco (2006).

Considerando que raça, em termos sociais e políticos, é um fator importante na constituição subjetiva dos sujeitos no Brasil, como se discutiu ao longo desta seção, seria relevante começarmos a questionar não somente em termos teóricos as relações raciais, mas também como essa dinâmica afeta a produção de conhecimento nos Estudos Organizacionais. Considerando as pesquisas qualitativas como métodos que produzem maior 
envolvimento dos pesquisadores na realização do trabalho de campo, será que o fato de um pesquisador ou pesquisadora ser negro/negra influenciaria o desenvolvimento da pesquisa nas organizações? Para discutir tal questionamento, na próxima seção deste artigo apresentamos a etnografia como método de pesquisa utilizado nos Estudos Organizacionais para possibilitar essa construção subjetiva entre os sujeitos na pesquisa, destacando como subjetividade e raça têm sido debatidos na construção desse método de pesquisa.

\section{SUBJETIVIDADE E RAÇA NA PRÁTICA ETNOGRÁFICA}

Realizar um estudo etnográfico requer um engajamento prático do pesquisador com o campo de pesquisa cujo efeito é a produção das vicissitudes de uma experiência emocional (MAGNANI, 2009). O contato cotidiano com os sujeitos na pesquisa, e não somente "da" pesquisa, possibilita, como afirma Magnani (2009), desconstruir o campo etnográfico como um ambiente exótico, pois ele passa a ser construído como um campo de contradições, regularidades e conflitos no qual a experiência pode gerar familiaridade com o não conhecido, aquilo que causa estranhamento.

Sendo assim, o método etnográfico implica uma dimensão política de realização da pesquisa. É uma construção política, pois se refere ao "encontro" de diferentes sujeitos que pode resultar na construção de um texto polifônico, na medida em que o etnógrafo se propõe a construir de forma colaborativa com os outros sujeitos na pesquisa o conhecimento etnográfico (CLIFFORD, 2008).

Atkinson et al. (2007) destaca que o acesso às informações em campo pode depender das relações que construímos com os "informantes-chave", aquelas pessoas que têm maior influência sobre as relações sociais no campo. As negociações para o acesso às informações também podem evidenciar, para o referido autor, temas ou espaços que são considerados "sagrados" ao campo de pesquisa e que, por isso, delimitam o que pode ou não ser apresentado na escrita do texto etnográfico. Então, mais que a ausência/presença em campo, são as conexões criadas durante a pesquisa que determinam o acesso às informações. Nesse sentido, a construção subjetiva que se realiza com os sujeitos no trabalho de campo é relevante para o desenvolvimento do estudo e acesso às "mirongas", ou aos segredos, (DIAS, 2007) que servirão de base para a construção do texto etnográfico.

Grossi (1992) afirma que esse processo de construção do campo etnográfico e do texto resultante da etnografia é influenciado pela construção e posicionamento social dos pesquisadores. 0 exemplo apresentado pela referida autora é a construção ideológica do gênero feminino como "emotivo" e suas implicações no desenvolvimento das pesquisas etnográficas. Grossi (1992) cita como exemplo o caso de uma pesquisadora mulher, solteira e "longe de sua família" que quase foi impedida de realizar sua etnografia pelo fato de ser considerada como uma "mulher de vida fácil" por não se constituir a partir das práticas esperadas de uma "mulher" no Ocidente, sendo esta casada, com filhos e acompanhada de sua família, por exemplo. É isso que Lutz e Abu-Lughod (1990) discutem ao afirmar que os discursos sobre as emoções possuem como retórica o controle das questões relacionadas a gênero, pois implícitos nas discussões sobre o feminino estão sinais de fraqueza das mulheres. Portanto, o discurso sobre emoções reflete relações de poder na sociedade e influencia 
a condução dos estudos etnográficos, pois posiciona os pesquisadores nas relações com outros sujeitos na pesquisa.

Em termos de raça, um estudo que destacou essa construção social não somente como tema de pesquisa, mas discutindo as influências de uma pesquisadora negra no desenvolvimento do trabalho de campo etnográfico, foi desenvolvido por Gomes (2002). A referida autora se posiciona como mulher negra e realiza um estudo em salões de beleza, na cidade de Belo Horizonte, Minas Gerais, especializados em cabelos crespos. Gomes (2002) discute a construção da "beleza negra" a partir das alterações realizadas pelas mulheres negras no corpo e nos cabelos articulando as suas experiências com as mulheres pesquisadas. Os resultados da pesquisa são apresentados em uma série de debates sobre como desde a infância as mulheres negras aprendem a "lidar" com os cabelos na feitura das tranças nos cabelos, o que é relembrado pela própria autora na construção de suas relações familiares, aprendidas entre mães e filhas. Outro exemplo discutido por Gomes (2002) é que os cabelos materializam os estigmas produzidos para representar essa população, especialmente pela transformação das representações do "cabelo ruim" em "nêgona" quando se deixa de alisar os cabelos deixando-os crespos.

É isso que as denominadas etnografias críticas (FOLEY; VALENZUELA, 1994) tentam colocar em debate quando afirmam que o trabalho de campo etnográfico também tem um caráter político, especialmente quando o contexto pesquisado faz parte da constituição sociohistórica do etnógrafo, a exemplo do estudo de Gomes (2002). Pinho (2008), discutindo o trabalho de Guber (1996), destaca que quando o objeto de pesquisa faz parte do processo de constituição do pesquisador, isso pode atuar como um instrumento heurístico nas análises da pesquisa. Isto porque a complexidade de determinadas vivências no campo de pesquisa só pode ser compreendida com base em reflexões a partir da posição enquanto um(a) pesquisador(a) nativo(a), ou seja, que integra o contexto social que se pretende analisar (PINHO, 2008). Com base nessas considerações, Pinho (2008, p. 10) questiona:

\begin{abstract}
No meu caso, o que significaria identificar-me como negro? Quem, desse ponto de vista, falaria, quando digo, no texto etnográfico, "eu"? O sentido da anedota banal que inicia esta seção é justamente procurar dar uma forma a esta interrogação. Como o "eu" da "vivência", ela mesma implicada na tessitura das relações raciais que pretendo interpretar, interpela o "eu" sujeito quase onisciente do texto etnográfico? Em que medida a necessidade de objetividade implica, assim, numa alienação das condições mesmas que permitem que o texto se inscreva?
\end{abstract}

As relações entre a construção subjetiva e raça na construção da etnografia devem ser apresentadas no texto etnográfico de forma que se evidencie "de onde o pesquisador" enuncia as suas interpretações. Isso porque são as nossas experiências cotidianas que são destacadas na realização da etnografia.

Ao considerarmos o racismo como um sistema de opressão no contexto brasileiro, ou seja, um sistema que opera no nível institucional na sociedade colocando os negros, de forma coletiva, em posições de inferioridade social (CARNEIRO, 2003), é importante destacar que não é a formação universitária que desconstrói ou neutraliza essa forma de 
opressão (FIGUEIREDO, 2002). Sendo assim, é desse lugar social que os pesquisadores negros realizam a pesquisa de campo.

Na prática de pesquisa, reconhecer a raça como fator essencial no trabalho de campo é um dos passos que o campo científico tem para enfatizar que "o subalterno possa 'falar', não extrinsecamente representado como o "ponto de vista nativo", mas como o autor" (PINHO, 2008, p. 10). Com efeito, o modo hierárquico de incorporação dos "nativos" na construção do texto etnográfico, sendo o etnógrafo quem detém o "poder", assim como as relações de alteridade são repensadas nesse contexto (PINHO, 2008). Há a possibilidade de uma inversão dessas posições devido ao lugar que os negros ocupam na sociedade.

De forma mais específica, no cotidiano de pesquisa, a raça, de acordo com Dewalt e Dewalt (2011), influencia a construção do projeto de pesquisa, as experiências do trabaIho de campo, assim como os sujeitos participantes da pesquisa constroem suas relações com os pesquisadores e o estudo. Isso porque nós somos construídos socialmente e se, socialmente, existem espaços duros (SANSONE, 2004) para os negros, a exemplo das relações afetivas, é preciso pensar como a construção das relações de afeto que possibilitam o jogo da alteridade e da entrada no campo etnográfico são perpassadas ou constituídas a partir dessa lógica que sustenta a sociedade brasileira, por exemplo. Em que medida as questões raciais têm impacto no acesso ao campo de pesquisa é uma questão que deve ser discutida, pois releva aspectos sobre como a relação da ciência com o senso comum também é estruturada a partir das relações pautadas em questões raciais.

Estudos como de Alcadipani, Westwood e Rosa (2015) já apresentaram debates sobre a necessidade de se discutir como aspectos socioculturais influenciam o trabalho de campo etnográfico. Os referidos autores discutem aspectos relacionados à identidade e à etnicidade nas pesquisas qualitativas, especialmente quando os pesquisadores são os "outros" e não possuem uma posição de centralidade nos estudos empíricos, seja essa centralidade em termos de produção de conhecimento ou social.

Neste estudo, buscamos avançar nessa discussão realizada por Alcadipani, Westwood e Rosa (2015) ao colocarmos em discussão as proximidades e distanciamentos dessa construção dos pesquisadores e não os "nativos" nos estudos etnográficos como sendo o "outro" em seu próprio país e em um país considerado centro do mundo, a partir de uma perspectiva racial. Sendo assim, buscamos contribuir com a área de Estudos Organizacionais no Brasil ao discutirmos como a raça influencia o trabalho de campo etnográfico em uma perspectiva transnacional, por isso, reportamo-nos a uma etnografia multilocalizada e transnacional para evidenciar as nuances das manifestações das relações raciais na realização de uma pesquisa qualitativa. Considerando os debates de Pinho (2008) acerca da necessidade de se considerar como as tessituras das relações raciais influenciam o trabalho de campo, bem como a posição de onde o sujeito que relata a etnografia enuncia, na próxima seção deste artigo apresentamos a construção metodológica da pesquisa. Destacamos que nessa seção o foco dos debates estará na construção da pesquisa, sendo que a dinâmica e as sutilezas das questões raciais na construção da etnografia são apresentadas nas seções seguintes deste artigo. 


\section{A ETNOGRAFIA MULTISSITUADA: A CONDUÇÃO DA PESQUISA DE CAMPO}

A pesquisa etnográfica iniciou-se durante o mês de março do ano de 2011, no Brasil, com um circo contemporâneo localizado na cidade de Pelotas, Rio Grande do Sul, sendo finalizado nesse primeiro local de pesquisa, durante o mês de dezembro daquele mesmo ano. 0 circo foi fundado na década de 1980 e tombado como patrimônio cultural gaúcho nos anos 2000, e será denominado de circo Alegria neste artigo. Organizado em forma de associação, o circo era composto por trinta e dois artistas e aproximadamente cem pessoas atuam em outras atividades nessa organização. 0 circo realiza suas atividades em três espaços: o Centro de Treinamentos (CT), o ateliê e as viagens para apresentações dos espetáculos.

Nesses três contextos de pesquisa, foram produzidos diários de campo, conforme preconiza o método etnográfico (CLIFFORD, 2008), como forma de sistematizar todas as experiências que a pesquisadora, denominada a partir de agora de Luísa, estava vivenciando em campo. Como afirma Dias (2007), a etnografia consiste em um fluxo no qual as coisas acontecem, e ao se deixar o devir da pesquisa ocorrer por meio de nossas experiências, a qualidade do trabalho de campo pode não ser comprometida. Isso se deve porque antes de se estabelecer uma visão romântica ou exótica do estudo, as contradições, reproduções ou questionamentos podem evidenciar como as construções dos objetos de pesquisa ocorreram sem cair em uma "eutnografia", sem acabar sendo um diário pessoal psicanalítico, discorre Dias (2007).

Ao iniciar a pesquisa de campo, entretanto, a excentricidade era uma característica atribuída à Luísa. Durante a rotina diária de treinamentos no CT, a qual era anotada em diários de campo, era comum que ao final da tarde ocorressem pausas para a alimentação. Nos primeiros dias em campo, Luísa se oferecia para sair e comprar algumas coisas para as refeições, como não os conhecia, ela solicitava a eles se tinham preferência por alguma marca de produtos. Em uma dessas ocasiões, uma das artistas perguntou à Luísa se ela poderia comprar água para eles. Ela disse que sim, e era somente dizer a marca de preferência dela. A resposta que a pesquisadora ouviu foi: "desde quando água tem marca?" (DIÁRIO DE CAMPO, 15 DE ABRIL DE 2011).

Além dos conhecimentos mercadológicos, que eram estranhos para os artistas do circo, Luísa evitava comportamentos que a descaracterizassem, nesse primeiro momento, com interesses profissionais em relação aos circenses. Por isso, inicialmente, ela evitava fazer fotografias das atividades realizadas no CT para que não fosse associada a uma "fã" do grupo. Também começou a incorporar em sua rotina cotidiana roupas de malha, tênis e os cabelos trançados ou amarrados para a execução das observações participantes, realizadas, especialmente, nas atividades do CT, que eram basicamente treinamentos com técnicas circenses, bem como acompanhar os artistas em seus cafés da tarde em uma padaria na cidade de Pelotas.

Flores-Pereira (2007), em uma etnografia realizada em uma livraria, discorre sobre como os sujeitos incorporam elementos da cultura organizacional durante a realização do trabalho de campo. A referida autora afirma que após ter realizado a etnografia em um referido espaço organizacional, até mesmo sua forma de caminhar havia sido alterada. Nesse sentido, é possível apreender que a experiência da pesquisa transforma práticas 
dos sujeitos não somente em relação à condução dos estudos, mas na construção de suas subjetividades.

Esses laços afetivos construídos durante a pesquisa de campo proporcionaram a Luísa adentrar ao mundo circense por meio das redes de amizades formadas entre os artistas de circo (CLIFFORD, 2008). Nessas conversas e convívio cotidiano com os artistas, os termos "nêga" ou "negão" eram utilizados como forma de materialização de uma relação afetiva de proximidade entre os sujeitos. Não raro, eram termos utilizados seguidos de abraços ou de sorrisos entre os sujeitos. É preciso destacar que a utilização do termo "negro" tinha um cunho político. Apesar de no cotidiano da cidade onde o circo se localiza ser comum a utilização do termo "moreninho" ou "moreninha" como forma de denominar as pessoas com tom de pele negra, os artistas reafirmavam a necessidade de serem denominados como "negras" ou "negros" para desconstruir a "negação da raça" (CONCEIÇÃO, 2009) como categoria social relevante para a compreensão e construção do contexto social brasileiro.

Nesse primeiro momento da pesquisa foram produzidos noventa e cinco diários de campo, trinta e uma entrevistas com os artistas circenses, de um total de quarente e dois artistas, sendo o roteiro pautado nas seguintes questões: (1) trajetórias de vida (família, formação educacional e profissional), (2) trajetória histórica no circo (ingresso e atividades desenvolvidas no grupo e nos elencos) e (3) trajetória histórica do circo pesquisado. Também foram produzidas aproximadamente quinhentas fotografias do cotidiano e dos espetáculos realizados pelo circo em conjunto com cinco horas de gravações de vídeos dos circenses.

A convivência cotidiana construída no circo também fez Luísa compreender as influências do circo contemporâneo produzido no Canadá no contexto brasileiro. Nas conversas cotidianas, especialmente quando relacionadas a trabalho, as falas dos integrantes do circo, inclusive da equipe técnica, eram de recorrentes elogios ao trabalho circense canadense. Além de assistirem os vídeos e espetáculos produzidos naqueles país, um banner de uma companhia circense fazia parte da decoração da companhia brasileira como forma de lembrança do dia em que eles puderam assistir a um espetáculo circense canadense. Sendo assim, Luísa percebia que o contexto local de produção circense brasileiro estava sendo influenciado pela produção artística no Canadá. Optou, então, por continuar o estudo naquele país.

A questão que se colocava nesse momento era como adequar metodologicamente a pesquisa, a partir dessa demanda do trabalho de campo. Luísa optou pela realização de uma etnografia multissituada como forma de incorporar essa dinâmica do campo estudado a pesquisa que estava sendo realizada. Cooke, Laidlaw e Mair (2009) destacam que os contextos locais são influenciados por "produção culturais globais" colocando como desafio aos etnógrafos repensar os tradicionais campos de pesquisa, constituídos por um local de realização da pesquisa para possibilitar compreender o campo etnográfico como sendo multi-localizado.

Marcus (1999) discute que na etnografia multissituada, os pesquisadores não apenas traçam os movimentos dos objetos de estudo, mas, o mais importante, eles traçam as relações sociais e articulações materiais desses movimentos podendo formar um "circuito cultural". Buscando uma aproximação com essa definição de etnografia multissituada, optamos por deslocar o local de análise e buscar decifrar as redes que possibilitam interconectar o contexto circense estudado no Brasil com o Canadense. Essa mobilidade dos 
locais da pesquisa etnográfica possibilita, de acordo com Marcus (1995), decifrar a rede de associações e conexões do objeto de estudo a partir da reconexão entre as dimensões do "mundo vivido" e o sistema mundo, pois a própria circulação do pesquisador nessa rede de interconexões é que possibilita reconstruir essa interconexão.

A pesquisa no Canadá foi realizada entre os meses de janeiro e setembro do ano de 2013 com um circo canadense fundado no início dos anos 2000 por sete artistas de circo. 0 coletivo circense, modo de organização dos artistas pesquisados naquele país, apresentava, no momento da realização da pesquisa, dez espetáculos de circo produzidos pelos artistas, sendo considerados pelos seus pares, no Canadá e no Brasil, como (re)inventores do circo contemporâneo, sem lona e sem animais, caracterizado pela ênfase dramatúrgica em seus espetáculos.

No contexto canadense, foram produzidos setenta e oito diários de campo e treze entrevistas com artistas circenses canadenses. 0 roteiro de entrevista foi o mesmo utilizado no Brasil, com a diferença de que as entrevistas foram conduzidas em língua francesa, língua oficial do Canadá, em conjunto com o inglês. Também foi produzido um conjunto de sessenta e oito fotografias do trabalho de campo.

A partir do material empírico produzido no trabalho de campo realizado por Luísa no Canadá, uma representação marcante na determinação da posição social da pesquisadora foi a figura da mulata (CORREA, 1996). Quando Luísa chegava nos espaços sociais canadenses e se identificava como brasileira, era essa a definição atribuída a ela. Um dos exemplos mais marcantes desse fato foi o processo seletivo para ingresso em uma residência estudantil na cidade de Montréal. Um os documentos necessários para a seleção na residência era uma fotografia. A partir dela, uma das diretoras da referida residência definiu Luísa como sendo uma "típica mulata brasileira" que residiria naquela localidade, visto que no Brasil a "mulata é a tal" (CORREA, 1996). Foi a partir dessa representação de uma "típica mulata brasileira" que Luísa experenciou no Canadá.

Esse material foi categorizado neste artigo a partir das categorias (1) representação da pesquisadora no trabalho de campo e (2) relações raciais, de forma que fosse possível, posteriormente, relacionar as duas categorias na composição das análises. Nesse sentido, a própria forma de inserção de Luísa nesses locais de pesquisa poderia revelar as dinâmicas das práticas e dos processos organizativos do circo contemporâneo em diferentes contextos culturais. É preciso destacar que por se tratar de um estudo etnográfico, os relatos da experiência do trabalho de campo são apresentados e analisados neste texto a partir da pesquisa realizada pela pesquisadora (Luísa). Para compreender como ocorreu essa construção do campo etnográfico com base na circularidade de (des)construção subjetiva da pesquisadora no contexto do circo contemporâneo, apresentamos, nas próximas seções deste artigo, os trabalhos de campo realizados no Brasil e no Canadá.

\section{AS INFLUÊNCIAS DAS RELAÇÕES RACIAIS NA CONSTRUÇÃO DA PESQUISADORA NO CAMPO CIRCENSE NO BRASIL}

Adentrar ao campo de pesquisa circense iniciou-se em maio de 2010 quando a orientadora de doutorado de Luísa a convidou a participar de um projeto sobre circos 
em parceria com outra universidade. Em um primeiro momento, o "estranhamento" com esse campo de pesquisa, do qual a pesquisadora possuía poucas informações, foi o que a instigou a aceitar a proposta. Para Luísa, essa era uma situação inusitada. Até então, ela considerava que o circo era praticado sob uma lona com adestramento de animais. Entendimento este que já configurava uma anedota em sua família, visto que quando Luísa era criança, e não gostava de ir ao circo, em mais uma tentativa de escapar dos passeios da escola quando o circo chegava à cidade, ela argumentou com sua mãe: "eu não vou porque os animais não tomam banho para esperar a gente!" (DIÁRIO DE CAMPO, 30 DE MARÇO DE 2011). Desde então, no âmbito de família e amigos próximos, "Luísa" e "Circo" eram "variáveis independentes".

A imersão teórica realizada ao escolher o circo como campo de pesquisa possibilitou a desconstrução o imaginário infantil que Luísa tinha do circense. 0 contato com os textos sobre a produção do "circo contemporâneo" sem lona, sem animais e com uma linguagem cênica que, por vezes, chega a ser dramatúrgica, evidenciou como esse campo artístico tem passado por um processo de reconstrução de suas práticas de organização, por vezes silencioso, e que nem por isso deixa de ser conflituoso. Fazer uma imersão etnográfica nesse contexto poderia então ser um importante mecanismo de compreensão dessa dinâmica que se revelava um desafio profissional e pessoal. Se durante o trabalho de campo, os "estranhamentos" em relação ao trabalho circenses foram desconstruídos, seria possível que o mesmo ocorresse no que se referia às representações simbólicas da pesquisadora durante a realização do método etnográfico?

Os primeiros questionamentos em relação à presença de Luísa no circo Alegria eram sobre a sua cidade de origem, visto que seu sotaque não era gaúcho. Assim como quando a pesquisadora ingressou no programa de doutorado em Administração na cidade de Porto Alegre, os artistas comentavam que nas cidades do interior do Rio Grande do Sul as pessoas que não são gaúchas são denominadas de "brasileiras". Por mais que os artistas afirmassem que não concordavam com tal denominação, alertavam Luísa para que não estranhasse quando fosse chamada de "brasileira" por algum sujeito na cidade.

A sensação de ser chamada de "brasileira" em seu próprio país, como se fosse uma estrangeira, não era das mais agradáveis. Entretanto, o constrangimento é uma experiência que pode ser extremamente reveladora na pesquisa etnográfica uma vez que destaca as tensões da mobilidade do trabalho de campo (CLIFFORD, 2008) do pesquisador durante as atividades de campo. Quando Luísa comentou com um colega de doutorado, ainda na cidade de Porto Alegre, sobre sua indignação frente a tal denominação, ele afirmou que isso também tinha relação com a "cor da pele" da pesquisadora, visto que, nas palavras dele, "brasileira" era toda pessoa com a cor da pele um pouco mais "moreninha". Ainda, a palavra era utilizada como sinônimo de pessoas não afetas ao trabalho e que valorizam o tempo de "ócio". No caso de Luísa, ela era considerada "brasileira" pelo fato de ser negra, afirmou o colega de doutorado.

Estudos como o de Kanaan (2013) evidenciam, especialmente no contexto da Serra Gaúcha, como tais estereótipos, embasados em discursos hegemônicos, agem de forma a homogeneizar grupos de sujeitos de distintas localidades ocultando as diferenças e contradições de cada "grupo" e estabelecendo certas condições de possibilidades para transitar e transpor estas fronteiras. De acordo com a referida autora, esses estereótipos 
quando vinculados às práticas de trabalho organizam os sujeitos em dois grupos, os "poucos trabalhadores", denominados de "brasileiros" ou negros, e os "muito trabalhadores", denominados de "gringos", que, no contexto gaúcho, se refere aos sujeitos de origem italiana e residentes na Serra Gaúcha (KANAAN, 2013). Outro aspecto importante destacado por Kanaan (2013) é que na localidade pesquisada o termo "negro" é utilizado para denominar as pessoas que não têm tom de pele claro, olhos claros ou cabelos loiros, sendo eles gaúchos ou não. Isso evidencia como a raça é um marcador simbólico predominante em relação à questão regional.

Na literatura nacional essa figura do "brasileiro" não afeto ao trabalho foi propagada por textos, a exemplo, de Sérgio Buarque de Holanda sobre o "homem cordial" ou de Mario de Andrade, que constrói a personagem Macunaíma para expressar a falta de caráter do brasileiro (KANAAN, 2013). No caso dos negros, esse processo de segregação pode ser observado nos textos de Nina Rodrigues ou de Gilberto Freyre. Esses discursos associados às práticas cotidianas determinam então quem pode e onde deve passar nos espaços públicos, bem como nos espaços organizacionais, conforme discutem Nascimento et al. (2013), Rosa (2012) e Conceição (2009).

Esses primeiros movimentos etnográficos no trabalho de campo evidenciavam como as diferenças entre os sujeitos fomentam práticas que delimitam simbólica e materialmente a circulação no espaço social, nas palavras de Certeau (2008), ou de significação do lugar, nas discussões de Cresswell (2006). É isso que Fonseca (2000) destaca ao afirmar que os estudos etnográficos realizados com base na antropologia das práticas têm ousado desmistificar o trabalho de campo como homogêneo buscando, no cotidiano de vida dos sujeitos sociais, reconhecer cada vez mais diferenças e compreender justamente as maneiras complexas em que essas diferenças se entrecruzam.

Essas diferenças de origem regional e de cor da pele atuavam, no contexto analisado, como uma permissão simbólica e material para designar quem era ou não daquele espaço social. E de certa forma o processo etnográfico estava confrontando essas fronteiras simbólicas determinadas pelo contexto social. Tais fronteiras de produção entre o "eu" e o "outro" se constituíram com base em um processo de racialização. Por isso Hall (1999) destaca que discutir raça se refere ao processo de compreensão de como a sociedade se organiza em torno de suas diferenças sociais, resultando no que Sansone (2004) afirma ser a produção de diferentes espaços sociais nos quais a raça é fator determinante para delimitar pertencimentos, o que ocorre no processo de pesquisa, mas também na própria universidade, que "estranha" a presença de negros em sua própria constituição, em alguns espaços.

Entretanto, o caráter político das relações sociais também possibilita a desconstrução da produção simbólica das relações entre o etnógrafo e os sujeitos na pesquisa, conforme pode ser observado no seguinte relato de um dos artistas circenses que participaram do estudo:

Quando me disseram que tinha alguém, que tava fazendo um trabalho sobre o grupo e que ia nos acompanhar e lembro bem de te olhar carregando o material [...] com uma vassoura na outra mão, eu pensei: "lá vem mais uma fãzinha tentando se infiltrar de qualquer jeito aqui dentro." Assim que me deste o primeiro "oi" seguido de uma breve conversa e um pedido de entrevista, 
já pude constatar que estava errado, nas tuas primeiras palavras já dava pra notar alguém com seriedade, uma doçura rara e um conhecimento e certeza daquilo que estava fazendo (TIAGO, CLOWN, 10 DE FEVEREIRO DE 2013).

É isso que Pinho (2008) e Clifford (2008) destacam ao afirmar que a etnografia é um processo político, pois se nós observamos e construímos nossos relatos do trabalho de campo, também somo (des)contruídos a partir das relações que estabelecemos com os sujeitos no campo de estudos. Esse processo, conforme discutem Marcus (1995) e Gomes (2003), ocorre devido ao contexto cultural no qual o pesquisador está inserido. No campo de pesquisa no Brasil, o termo "negro", conforme discutido ao longo deste artigo, significava a existência de uma relação afetiva próxima entre os sujeitos. Não raro, os artistas chegavam para iniciar os trabalhos e comentavam "oi, nêga" (DIÁRIO DE CAMPO 15 DE ABRIL DE 2011), seguido de manifestações de afeto.

Uma das artistas negras utilizava os cabelos soltos no estilo black power, conforme debate Gomes (2003), como forma de resistência frente aos padrões de beleza centrados nos cabelos lisos. Outro artista, também negro, conversava cotidianamente com os colegas sobre a situação de discriminação da população negra no Brasil e no mundo, e caso alguém utilizasse algum termo considerado como forma de reprodução do racismo, ele comentava com o colega sobre a origem desses termos e a necessidade de não o reproduzir como forma de romper com situações de discriminação na sociedade (DIÁRIO DE CAMPO 30 DE JUNHO DE 2011). Retomando as discussões de Sansone (2004), era uma tentativa de transformar o espaço organizacional em um "espaço leve" ou "espaço negro" no cotidiano circense.

Esse processo possibilitava Luísa ser reconhecida como negra e não como "brasileira" na organização pesquisada, ao contrário do que ocorria, por vezes, no espaço público da cidade. Com efeito, a pesquisadora tinha acesso não somente aos debates sobre a constituição profissional dos circenses, mas também às lutas políticas colocadas naquele cotidiano organizacional, especialmente as raciais.

Nesses debates, também eram acionados exemplos de outros países como forma de discutir o contexto de trabalho no circo, especialmente em relação à diversidade de origem dos artistas. Uma das referências utilizadas pelos artistas para a construção de seu trabalho era o circo canadense, tanto em termos de diversidade cultural de constituição dos elencos dos espetáculos, bem como das técnicas circenses. Essa consideração do circo canadense como referência das práticas de organização do circo brasileiro me instigou a continuar o estudo no Canadá, adotando a etnografia multissituada como estratégia metodológica (MARCUS, 1995) para compreensão desse processo organizativo multicultural e multilocalizado, o que será debatido na próxima seção deste artigo.

\section{A CONSTRUÇÃO SIMBÓLICA DA "BRASILEIRA" NO CANADÁ: RELAÇ̃̃ES RACIAIS NA CONSTRUÇÃO DA PESQUISA DE CAMPO}

Para a realização da pesquisa no Canadá, Luísa optou por residir na cidade de Montréal em uma residência universitária, cuja uma das três diretoras era brasileira, o que 
poderia proporcionar uma "âncora cultural" em seu processo de mudança de país. Das outras duas diretoras, uma era espanhola e outra canadense. Conforme discute Marcus (1995), o trabalho de campo multissituado é, portanto, sempre conduzido com uma consciência de estar dentro da paisagem e como a paisagem muda em diferentes locais a identidade do etnógrafo exige renegociação. 0 fato de Luísa ser brasileira influenciaria diretamente as suas relações em campo, pois seriam as "representações" do Brasil que também estariam em jogo nessa relação. Uma dessas representações foi marcante durante a etnografia no Canadá: a figura da "mulata" (GOMES, 2003; SANCONE, 2004; CORREA, 1996). Um os documentos necessários para a seleção na residência onde a pesquisadora iria morar em Montréal era uma fotografia. A partir dela, a diretora brasileira da residência definiu "Luísa" para as outras gestoras da casa como sendo uma "típica mulata brasileira" (GOMES, 2003; CORREA, 1996). Foi a partir dessa representação de uma "típica mulata brasileira" que Luísa chegou ao Canadá.

Já no mês de fevereiro de 2013, um mês após a chegada de Luísa ao Canadá, era época de carnaval no Brasil, e em uma conversa entre alguns colegas em uma das universidades em Montréal, na qual somente a pesquisadora era brasileira, um dos garotos disse: "Nossa! Eu estava assistindo as propagandas do carnaval no Brasil. E que coisa são as mulheres brasileiras", com gestos como se a personagem em sua mente tivesse seios grandes (DIÁRIO DE CAMPO, 28 DE FEVEREIRO, DE 2013). Luísa começava a descobrir como as manifestações preconceituosas em relação à figura da "mulata" (CORREA, 1996) também se reproduziam no Canadá.

Esses tipos de comentários que se estenderam ao longo da estadia de Luísa na cidade eram formas de apagamento do sujeito, pois representava um mecanismo de materialização de uma formação discursiva (mulata) no corpo da pesquisadora (FOUCAULT, 2010). Então, o próprio corpo de Luísa seria um mecanismo de negociação política com o campo, pois era a construção subjetiva da "típica mulata brasileira" que influenciava, em um primeiro momento, o seu acesso ao campo de pesquisa naquele país. Por isso, Sansone (2002) destaca que o racismo é uma ideologia que pode parasitar categorias sociais na produção política da sociedade, nesse caso as articulações entre raça, gênero e nacionalidade produziam Luísa como "mulata" no Canadá. Importante destacar que, como afirma Hall (1999), essa dinâmica discursiva do processo de racialização dos sujeitos faz com que as representações associadas a elas não tenham fronteiras transitando entre diversos espaços sociais, a exemplo do Brasil e do Canadá sobre a mulher negra brasileira.

Na primeira reunião com os gestores do circo pesquisado no Canadá, as representações raciais da "típica brasileira" e da "brasilidade" foram essenciais para o acesso ao campo etnográfico. Na hora agendada com o gestor do circo que seria pesquisado, Luísa chegou ao escritório da companhia, sentou-se no sofá mais próximo da entrada de uma sala identificada de "comunicação" e esperou ser anunciada pela secretaria ao diretor da organização (DIÁRIO DE CAMPO, 11 DE MARÇO DE 2013). Logo em seguida, uma senhora, vestida de vermelho, abordou Luísa dizendo, em francês "Bom dia, senhorita". A pesquisadora sorriu e como estava ainda em seus primeiros meses de adaptação ao sotaque francês canadense, tinha medo de não compreender ou de responder qualquer questionamento de forma incorreta. A senhora, observando o silêncio de Luísa e a atenção a sua fala, continuou: você não fala? Seguida de risadas de ambas (DIÁRIO DE CAMPO, 11 DE MARÇO DE 2013). Quando ela identificou que Luísa era brasileira, o seu semblante de 
surpresa e admiração indicavam a curiosidade pelo seu país. Entretanto, não houve tempo para mais conversas a respeito dos "estranhamentos culturais" entre elas, pois a senhora saiu para atender a um chamado de um colega de trabalho.

Quando o diretor artístico do circo chegou à recepção do escritório, questionou Luísa se ela gostaria de falar em inglês ou francês, visto o Canadá ser um país bilíngue. A pesquisadora solicitou o francês, pois sabia da predominância da colonização dos franceses na localidade em estudo, sendo convidada a conhecer o escritório. Em todas as salas, quando o diretor do circo apresentava Luísa, as pessoas desejavam boas-vindas manifestando preocupação em relação à adaptação de uma brasileira ao "clima frio" canadense (DIÁRIO DE CAMPO, 11 DE MARÇO DE 2013). Na sala destinada à equipe de produção dos espetáculos, a pesquisadora foi questionada se iria "trabalhar" com o circo, afinal, para "alguém se interessar em estudar circo no doutorado é porque tem paixão pela arte" (DIÁRIO DE CAMPO, 11 DE MARÇO DE 2013).

Os brasileiros, de forma geral, eram representados como um "povo alegre" pelos canadenses. Durante a pesquisa, quando as conversas em campo se direcionavam para a nacionalidade de Luísa, assim como de seus traços raciais, era comum a associação do Brasil com a capoeira, com o carnaval, à utilização de roupas coloridas ou aos excessos com a alimentação. Sobre esse último aspecto, em um dos dias de ensaios de espetáculo, Luísa se comprometeu a levar comidas típicas brasileiras para um lanche da tarde no circo. Quando a pesquisadora chegou ao ensaio com os pratos de comidas típicas, uma das artistas afirmou "Isso é comida para mais ou menos dois dias por aqui. No Brasil é assim não é mesmo?" (DIÁRIO DE CAMPO, 4 DE JULHO DE 2013). Sobre essas discussões, Tidaffi (2006, p. 62-63) afirma:

É indiscutível que a mídia internacional apresenta o Brasil como o paraíso do sol, das belas praias, das mulheres quentes dos trópicos, do carnaval, do samba e de outros ritmos frenéticos que destacam o molejo sensual dos casais. [...] 0 mundo solar dos trópicos é associado à sensualidade ("Não existe pecado do lado de baixo do Equador"). [...] 0 calor abrasador dos trópicos constituiria, portanto, um elemento naturalizador de comportamentos sensuais, mais espontâneos e abertos.

O "calor" do brasileiro era considerado como sendo algo "simpático" aos olhos dos canadenses, assim como sua relação com a capoeira, o carnaval e a figura da mulata. Aqui reside um ponto de reflexão importante sobre como a raça influencia o trabalho de campo etnográfico. Se no Brasil havia um distanciamento do campo em relação à associação do Brasil com traços culturais negros, no Canadá a "brasilidade" e a "negritude" eram a todo momento considerados como imbricados.

Ainda durante a primeira reunião da pesquisadora com o diretor geral do circo, ele afirmou que alguns de seus melhores amigos em Montréal eram brasileiros, conduziu-a até uma das janelas da sala de reunião do escritório do circo e solicitou que ela observasse a última janela do prédio ao lado do qual estavam (DIÁRIO DE CAMPO, 11 DE MARÇO DE 2013). Disse ele "lá, reside uma grande amiga minha, artista plástica, que veio de São Paulo. Observe as peças que tem na sala dela. Todas são muito bonitas. Um dia, quem sabe, a gente pode fazer uma reunião lá em casa e eu lhe apresento ela" (DIÁRIO DE CAMPO, 
20 DE MAIO DE 2013). A sua admiração pelo trabalho desenvolvido por uma brasileira poderia, talvez, ter pesado em sua decisão de aceitar a realização do estudo etnográfico com a organização para além das representações estereotipadas do país, porém, esse não é um fator que foi evidenciado como relevante para a decisão de aceite em participar do estudo.

É preciso destacar que esse início de inserção da pesquisadora em campo denota um processo de racialização do Brasil associado às representações da capoeira, das roupas coloridas, de um "povo caloroso". É isso que Hall (1999) destaca ao afirmar que raça é uma construção simbólica e não biológica que funciona como marcas simbólicas que diferenciam socialmente um grupo de outro. Sendo assim, a construção racial de Luísa como sendo uma "típica brasileira", uma mulata, determinou a forma como a pesquisadora entrou em campo e transitou nos espaços necessários para o desenvolvimento da pesquisa etnográfica.

\section{CONSIDERAÇÕES FINAIS}

Com o objetivo de compreender as influências das questões raciais na construção do campo etnográfico, apresentamos neste artigo como o fato de uma pesquisadora ser mulher negra influenciou o desenvolvimento de uma etnografia organizacional multissituada no processo organizativo do circo contemporâneo. Isso porque, ainda que os estudos etnográficos nos Estudos Organizacionais tenham problematizado questões de etnicidade e identidade (ALCADIPANI; WESTWOOD; ROSA, 2015), raça ainda é um tema pouco debatido nas pesquisas etnográficas (DEWALT; DEWALT, 2011), e ainda silenciado ainda nos Estudos Organizacionais (CONCEIÇÃO, 2009).

Nesse sentido, conforme discute Pinho (2008), o "eu" da "vivência" na pesquisa etnográfica está implicado na tessitura das relações raciais que constituem as etnografias, especialmente as organizacionais. Assim como para Pinho (2008), consideramos que a necessidade da objetividade buscada nas pesquisas organizacionais, ainda que combatida em termos teóricos, não pode resultar na alienação dos debates das condições sociais nas quais o texto etnográfico se constitui. Isso ficou evidenciado ao longo deste texto ao destacarmos como Luísa construiu o acesso ao campo de pesquisa em diferentes contextos culturais, sendo que as relações raciais foram determinantes nesse processo. No Brasil, Luísa era considerada brasileira pelo fato de ter a pele mais "moreninha", termo utilizado pelos sujeitos como sinônimo da pele negra. Já no Canadá, Luísa foi considerada brasileira por ser efetivamente negra e representar o estereótipo da "mulher brasileira".

No Brasil, as relações raciais influenciaram a realização da pesquisa no desvelamento das disputas regionais que existem no país, materializadas na construção do sentido de emprego da palavra "brasileiro" pelos gaúchos. Ainda que a pesquisa tenha sido realizada no Brasil, Luísa era considerada "brasileira" pelo fato de ser negra e isso denota as construções políticas e ideológicas do conceito de raça no país (SANSONE, 2004). Desse modo, considerando os relatos do trabalho de campo que apresentavam as pessoas com a "cor da pele" mais "moreninha", assim como as discussões do trabalho de Kanaan (2013) sobre como as pessoas "moreninhas" são posicionadas como "outro", mesmo sendo gaúchas, é possível compreender que a questão racial se sobrepõe às diferenciações regionais que poderiam existir nesse contexto, pelo fato de Luísa não ser gaúcha. 
Já no contexto do circo brasileiro pesquisado neste estudo, a conotação política do termo "raça" era utilizada como forma de resistência pelos artistas frente ao contexto cultural no qual a organização estava inserida. E isso era materializado nas falas e no corpo dos artistas, por isso os termos "nêgo", "nêga" ou "negão" eram utilizados como forma de aproximação afetiva entre os artistas, bem como da necessidade de se repensar e se ressignificar as diferenças culturais entre os artistas. Isso pode ser destacado pelo fato de os artistas negros enfatizarem a relevância de serem chamados de "negros" e não de "moreninhos", como era comum na vida cotidiana daquela localidade. Pelo fato de ser negra, Luísa era "chamada" a participar desses embates ao participar das discussões sobre as questões raciais no circo.

No Canadá, o fato da pesquisadora ser negra foi associado ao Brasil por meio da mobilização das representações simbólicas da "mulata brasileira", portanto, raça e nacionalidade também foram temas articulados naquele contexto social. Entretanto, o termo "brasileiro" foi condicionado a outras construções simbólicas que influenciaram o trabalho de campo, a exemplo do Brasil ser um país "caloroso" e "afetivo", o que, na inserção no campo organizacional circense, facilitou o acesso e as condições de realização do estudo. Outros dois aspectos importantes na realização da etnografia foram as relações de amizades construídas pelo diretor do circo com outros brasileiros, bem como a dimensão econômica do mercado artístico. Em relação às amizades com os brasileiros, a admiração pelos trabalhos desenvolvidos pelos conterrâneos foi evidenciada pelo diretor do circo, produção esta que pode ter influenciado a aceitação de realização do estudo com os circenses. $\mathrm{Na}$ dimensão econômica, o fato de o circo estar em processo de negociação de uma turnê no Brasil no momento da negociação do início do trabalho de campo também influenciou a aceitação de realização da pesquisa devido à possibilidade de os canadenses terem acesso às informações das relações de mercado com o Brasil.

É isso que Marcus (1995) destaca ao afirmar que nas etnografias multissituadas a circularidade do etnógrafo no trabalho de campo influencia a construção dos relatos etnográficos. Nesse sentido, essa proposição de Marcus (1995) sobre o trabalho de campo pode ser relacionada às discussões de Sansone (2004) e de Pinho (2008, p. 4) sobre a necessidade de desconstruir e a visão mítica no campo científico que relega aos negros 0 papel de portador de "cultura e não de um ser histórico, presente nas lutas sociais (e culturais), inclusive naquelas que conformam o mesmo campo acadêmico que o elegeu como objeto". Isso requer que as etnografias organizacionais discutam como a construção social dos pesquisadores em campo influenciam a produção de conhecimento, reconhecendo a produção de subjetividades não somente pelos sujeitos da pesquisa, mas dos sujeitos na pesquisa, o que inclui quem realiza o trabalho de campo.

Com efeito, esperamos que as discussões propostas neste artigo possibilitem que as relações raciais sejam problematizadas não somente como objeto de estudo, mas que coloquem em debate como a construção política e ideológica do conceito de raça e, especialmente, dos negros no país, não sejam limitadas a teorias tão pouco a serem "objetos" de estudo, mas possam ser pensadas a partir das vivências dos pesquisadores em campo. Sejam nas etnografias ou no trabalho nas universidades, é importante discutir como o engajamento subjetivo do pesquisador com o campo de pesquisa influencia a construção das pesquisas qualitativas e o quanto as relações raciais ainda são demarcadoras de "espaços pesados", "espaços leves" e "espaços negros" (SANSONE, 2004) na sociedade brasileira, 
funcionando como "fronteira simbólica" de quem pertence ou não a tais espaços, de quem pode ou não etnografar em determinados espaços sociais, bem como as formas de resistência da população negra frente a esse contexto social.

\section{REFERÊNCIAS}

ALCADIPANI, R.; WESTWOOD, R.; ROSA, A. The politics of identity in organizational ethnographic research: Ethnicity and tropicalist intrusions. Human Relations, v. 68, p. 79- 106, 2015.

ATKINSON, P. et al. Handbook of Ethnography. London: Sage, 2007.

CARNEIRO, S. Enegrecer o feminismo: a situação da mulher negra na América Latina a partir de uma perspectiva de gênero. In: ASHOKA EMPREENDIMENTOS SOCIAIS; TAKANO CIDADANIA (Orgs.). Racismos contemporâneos. Rio de Janeiro: Takano Editora, 2003. p. 49-58.

CARRIERI, A. P.; SARAIVA, L. A. S. Simbolismo Organizacional no Brasil. São Paulo: Atlas, 2007.

CECCHETTO, F.; MONTEIRO, S. Discriminação, cor e intervenção social entre jovens na cidade do Rio de Janeiro (RJ, Brasil): a perspectiva masculina. Revista Estudos Feministas, v. 14, n.1, p. 199-218, 2006.

CERTEAU, M. A invenção do cotidiano: artes de fazer. Petrópolis: Vozes, 2008.

CLIFFORD, J. A experiência etnográfica, Rio de Janeiro: UFRJ, 2008.

. Route: travel and translation in the late twentieth century. Cambridge: Harvard University Press, 1997.

CONCEIÇÃO, E. B. A negação da raça nos estudos organizacionais. In: ENCONTRO ANUAL DA ASSOCIAÇÃO NACIONAL DE PÓS-GRADUAÇÃO E PESQUISA EM ADMINISTRAÇÃO, 33, 2009, São Paulo. Anais... Rio de Janeiro: ANPAD, 2009.

COOKE, J.; LAIDLAW, J.; MAIR, J. What if There is No Elephant? Towards a Conception of an Un-sited Field. In: FALZON, M. A. Multi-Sited Ethnography: Theory, Praxis, and Locality in Contemporary Social Research. London: Ashgate, 2009, p. 47-72.

CORREA, M. Sobre a invenção da mulata. Cadernos PAGU, v. 6, n. 1, p. 35-50, 1996.

CRESSWELL, T. On the move: mobility in the modern western world. London: Routledge, 2006.

CZARNIAWSKA, B. Organizations as obstacles to organizing. In: ROBICHAUD, D.; COOREN, F. (eds.). Organization and organizing: materiality, agency and discourse. New York: Routledge, 2013. p. 3-22.

DEWALT, K. M.; DEWALT, B. R. Participant observation: a guide for fieldworkers. Toronto: Altamira Press, 2011. 
DIAS, M. A. Essa pesquisa tem "mironga": notas etnográficas sobre o fazer etnográfico. In: BONETTI, A.; FLEISCHER, S. (orgs.). Entre saias justas e jogos de cintura. Florianópolis: Editora Santa Cruz do Sul: EDUNISC, 2007.

FANTINEL, L. D.; CAVEDON, N. R.; FISCHER, T. Significados permanentes e mutantes: sociabilidades e significações no cotidiano de um café. Revista Ciências Sociais Unisinos, v. 50 , p. $153-165,2014$.

FIGUEIREDO, M. D. Embodied prejudices: a study on diversity and practices. Equality, Diversity and Inclusion: An International Journal, v. 34, p. 527-538, 2015.

. A transmissão do saber-fazer enquanto intencionalidade incorporada. 2013. $285 f$. Tese (Doutorado em Administração) - Programa de Pós-Graduação em Administração da Universidade Federal do Rio Grande do Sul, Porto Alegre, 2013.

FIGUEIREDO, A. Novas Elites de Cor: estudo sobre os profissionais liberais negros de Salvador. São Paulo: Annablume, 2002.

FLORES-PEREIRA, M. T.; DAVEL, E.; CAVEDON, N. Drinking beer and understanding organizational culture embodiment. Human Relations, v. 61, p. 1007-1026, 2008.

FOLEY, D.; VALENZUELA, A. Critical ethnography. In: DENZIN, N. K.; LINCOLN, Y. S. Handbook of Qualitative Research. 3 ed. Thousand Oaks: Sage, 1994.

FONSECA, C. Família, fofoca e honra: a etnografia de violência e relações de gênero em grupos populares. Porto Alegre: Editora da UFRGS, 2000.

FOUCAULT, M. O sujeito e o poder. In: RABINOW, P.; DREYFUS, H. L. Michel Foucault: uma trajetória filosófica. 2 edição. Rio de Janeiro: Forense Universitária, 2010, p. 296-342.

GHERARDI, S. How to conduct a practice-based study. Cheltenham: Edward Elgar, 2012.

GOMES, N. Trajetórias escolares, corpo negro e cabelo crespo: reprodução cultural ou resignificação cultural? Revista Brasileira de Educação, n.21, p.39-51, set./dez. 2002.

GONZALEZ, L.; HASENBALG, C. Lugar de negro. Rio de Janeiro: Marco Zero, 1982.

GROSSI, M. P. Na busca do "outro" encontra-se a "si mesmo". In: LAGO, C. (ed.). Trabalho de Campo \& Subjetividade, Florianópolis: UFSC/Grupo de Estudos de Gênero \& Subjetividade, p. 7-18, 1992. Disponível em: <http://miriamgrossi.paginas.ufsc.br/files/2012/03/ Visualizar7.pdf>

HALL, S. A identidade cultural na pós-modernidade. Rio de Janeiro: DP\&A, 1999.

INSTITUTO BRASILEIRO DE GEOGRAFIA E ESTATÍSTICA (IBGE). Censo demográfico 2010. Disponível em <https://censo2010.ibge.gov.br/apps/atlas/>. Acesso em 28 de abril de 2015.

KANAAN, B. R. Homo Faber: uma etnografia das práticas de trabalho na Serra Gaúcha/ Rio Grande do Sul. 2013. 230f. Tese (Doutorado em Antropologia Social) - Universidade Federal do Rio Grande do Sul, Porto Alegre, 2013.

LUTZ, C.; ABU-LUGHOD, L. Language and the politics of emotion. Cambridge: Cambridge University Press, 1990. 
MAGNANI, J. G. C. Etnografia como prática e experiência. Horizontes Antropológicos, Porto Alegre, ano 15, n. 32, p. 129-156, jul./dez. 2009.

MARCUS, G. E. Ethnography in/of the world system: the emergence of multi-sited ethnography. Annu. Rev. Anthropol, v. 24, p. 95-117, 1995.

MARCUS, G. E. What is at stake - and is not - in the idea and practice of multi-sited ethnography. Canberra Anthropology, v. 22, n. 2, p. 6-14, 1999.

NASCIMENTO, M. C. R. et al. Com que cor eu vou pro shopping de BH que você me convidou? In: ENCONTRO ANUAL DA ASSOCIAÇÃO NACIONAL DE PÓS-GRADUAÇÃO E PESQUISA EM ADMINISTRAÇÃO, 37, 2003, Rio de Janeiro. Anais ... Rio de Janeiro: ANPAD, 2013.

NOGUEIRA, O. Preconceito racial de marca e preconceito racial de origem: sugestão de um quadro de referência para a interpretação do material sobre relações raciais no Brasil. Tempo Social, v. 19, n. 1, p. 287-308, 2007.

PARKER, M. Organizing the circus: the engineering of miracles. Organization Studies, v. 32, n. 4, 2011, p. $555-569$.

PINHO, O. A Antropologia no Espelho da Raça. In: REUNIÃO DA ASSOCIAÇÃO BRASILEIRA DE ANTROPOLOGIA, 26, 2008. Porto Seguro, Bahia. Anais... Porto Seguro: ABA, 2008.

ROSA, A. R. Relações raciais e Estudos Organizacionais no Brasil. Revista de Administração Contemporânea, v. 18, n. 3, p. 240-260, 2014.

ROSA, A. R. Relações raciais e estudos organizacionais no Brasil: dimensões esquecidas de um debate que (ainda) não foi feito. In: ENCONTRO ANUAL DA ASSOCIAÇÃO NACIONAL DE PÓS-GRADUAÇÃO E PESQUISA EM ADMINISTRAÇÃO, 36, 2012, Rio de Janeiro. Anais... Rio de Janeiro: ANPAD, 2012.

SANSONE, L. Negritude sem etnicidade. Rio de Janeiro e Salvador: Pallas e EDUFBA, 2004.

Data de submissão: 30/08/2016.

Data de aprovação: 18/10/2017. 